\title{
Reciprocal Genetic Transformation Between Neisseria catarrhalis and Moraxella nonliquefaciens
}

\author{
By B. W. CATLIN \\ Department of Microbiology, Marquette University School of Medicine, Milwaukee, \\ Wisconsin, U.S.A.
}

(Received 19 May 1964)

\begin{abstract}
SUMMARY
Deoxyribonucleate (DNA) preparations from Moraxella nonliquefaciens elicited genetic transformation of Neisseria catarrhalis recipient cells, and vice versa. The frequency was low $(0.0005 \%$ transformation for the most reactive of six strains), as might be expected of an interaction between two organisms as dissimilar as a rod and a coccus. Evidence that the hereditary change (attainment by susceptible cells of resistance to $500 \mu \mathrm{g}$. dihydrostreptomycin $/ \mathrm{ml}$.) was due to transformation was provided by the typical time course of the reaction, the typical linear response to decreasing concentrations of DNA below $0 \cdot 1 \mu \mathrm{g} . / \mathrm{ml}$., and by tests of transforming activity of DNA preparations extracted from 11 dihydrostreptomycin-resistant $(s t r-r)$ strains which arose by intergeneric transformation. These DNAs had relatively high transforming activity for recipient strains of both species. Thus, the str-r region of the transforming DNA molecule from a transformant strain of $M$. nonliquefaciens was recognized and genetically integrated by populations of $N$. catarrhalis recipient cells at frequencies as much as 10,000 times higher than those of DNA from strains of $M$. nonliquefaciens str- $r$ (derived by spontaneous mutation). The results with DNA preparations from particular transformants are interpreted as indicating that the length of a DNA nucleotide sequence which is integrated by a cell during str-r transformation may differ for different cells of the same treated population.
\end{abstract}

\section{INTRODUCTION}

The Gram-negative diplococcus Neisseria catarrhalis and the Gram-negative diplobacillus Moraxella nonliquefaciens are both inhabitants of the mucosa of man. Both are oxidase-positive, unable to produce acid from carbohydrates, and are susceptible to many antibiotics, including penicillin and streptomycin. Recognition of various resemblances led Henriksen (1952) to suggest that the genus Moraxella might appropriately be placed in the family Neisseriaceae. In general, however, the similarities have been considered to be too superficial to indicate any real relationship (Murray \& Truant, 1954).

Do such apparent physiological similarities of Neisseria catarrhalis and Moraxella nonliquefaciens actually indicate a significant degree of genetic relationship? This question can now be raised because methods for detecting genetic homologies have become available. As discussed by Marmur, Falkow \& Mandel (1963) several methods, including genetic transformation, can be applied in experimental studies 
of taxonomic and evolutionary relationships of bacteria. Such studies are in progress with several groups of bacteria (e.g. Ravin \& De Sa, 1964), and many more will be required before we shall have accumulated a body of information sufficient for adequate interpretation of the genetic data and application to particular taxonomic problems.

Transformation involving streptomycin resistance is a highly sensitive method for detecting homology of a particular genetic determinant. Successful transformation of a coccus by deoxyribonucleate (DNA) from a bacterium has not been reported heretofore. In principle, however, differences relating to cellular morphology should not forbid the transfer of genetic information relating to streptomycin resistance, provided that the genetic determinants of morphological characteristics and of response to streptomycin are not associated with the same transforming DNA molecule.

Critical evaluation of the possible occurrence of genetic transformation of a member of one species by DNA extracted from cells of a different species requires a reliable test system, as well as availability of highly transformable strains of both species in order that reciprocal transformation tests can be performed. These requirements are satisfied for both Neisseria catarrhalis and Moraxella nonliquefaciens (Catlin \& Cunningham, 1964, $a, b$ ). Though transformation between members of the two species occurred at frequencies far lower than those characteristic of intraspecific transformation, it was amenable to study.

\section{METHODS}

The streptomycin-susceptible $(s t r-s)$ recipient strains and the transformation methods used with each have been described in detail (Catlin \& Cunningham, $1964 a, b)$. In brief the method involved three steps: (i) A homogeneous suspension of recipient organisms was prepared from a culture on HIY-1 agar, which had been incubated for $12 \mathrm{hr}$ at $30^{\circ}$ (Moraxella nonliquefaciens) or at $35^{\circ}$ (Neisseria catarrhalis). Microscopic examination of suspensions of $N$. catarrhalis strain 8313 showed 95-100\% of the presumptive colony-forming units to be single cocci or diplococci. Suspensions of other strains were not so homogeneous, but only $N$. catarrhalis strain Ne 11 showed a pronounced tendency toward cluster-formation. (ii) Recipient organisms were added to each DNA preparation (final concentration $25 \mu \mathrm{g}$. DNA/ml. for $M$. nonliquefaciens recipients, $5 \mu \mathrm{g}$. DNA $/ \mathrm{ml}$. for $N$. catarrhalis). After incubation at $30^{\circ}$ for 30 min., inactivating deoxyribonuclease was added. (iii) Appropriate dilutions were plated in HIY-1 agar to determine numbers of colony-forming units exposed, and transformants elicited. Transformant assay plates (8/sample) were incubated at $30^{\circ}\left(M\right.$. nonliquefaciens strain 19116) or at $3^{\circ}$ (all other strains). The duration of this incubation varied, depending on the time required for phenotypic expression of the particular strain: $M$. nonliquefaciens $7 \mathrm{hr}, N$. catarrhalis strain $\mathrm{Ne} 115 \mathrm{hr}$, all other $N$. catarrhalis strains $6 \mathrm{hr}$. Thereupon, the surfaces were overlaid with medium containing dihydrostreptomycin sulphate at a concentration to give $500 \mu \mathrm{g} . / \mathrm{ml}$. after diffusion throughout the underlying agar. Thirty min. later the plates were returned for further incubation. Colonies growing on this medium are designated $s t r-r$. Results are expressed as percent transformation: number of $s t r-r$ transformants/100 str-s cells exposed. 
Each experiment included a control, similar to other tests in all details except that the DNA (autologous) was inactivated with deoxyribonuclease $5 \mathrm{~min}$. before addition of recipient organisms. It was sampled last, and always within $80 \mathrm{~min}$. of the time of initial exposure of organisms to DNA. Thus, the organisms of all tests were distributed in agar within $\mathbf{5 0}$ min. of addition of deoxyribonuclease, a precaution to decrease possible error due to multiplication of a rare spontaneous mutant. These were not encountered with concentrations of test organisms below $10^{7} / \mathrm{ml}$, and only rarely at higher concentrations.

DNA preparations from str-r strains described previously (Catlin \& Cunningham, $1964 a, b)$ were used in exploratory tests. Colonies appearing on various transformant assay plates were subcultured. Each strain was inspected microscopically and examined for oxidase reaction, response to antibiotics, reaction in the presence of glucose, maltose and sucrose, capacity to produce deoxyribonuclease and gelatinase, and to reduce nitrate and nitrite (Catlin \& Cunningham, 1964 $a, b$ ). DNA was extracted from 12 selected strains, and was purified by methods previously described (Catlin \& Cunningham, 1961, 1964a).

Strains used as recipients in the transformation tests were selected on the basis of three characteristics: DNA base composition (representatives of different guanine+cytosine classes were examined), transformability, and tendency of clusters of organisms to become dispersed during preparation of suspensions. Ratios of percentage transformation by a given heterologous DNA to percentage transformation by autologous DNA, which were obtained in duplicate experiments with each recipient strain, were in close agreement.

The term 'autologous' (employed by Bracco, Krauss, Roe \& MacLeod, 1957) will be used here to refer to the reaction between a given str-s recipient strain and DNA extracted from a str-r strain derived by spontaneous mutation from that $s t r-s$ strain. The term 'homologous', normally applied to intraspecific reactions, is inappropriate here because of the differences between the strains presently classified as Neisseria catarrhalis (Catlin \& Cunningham, 1964 a). Therefore, 'heterologous' will be applied to all reactions between organisms and DNA of different origins.

\section{RESULTS}

Treatment of Neisseria catarrhalis recipient organisms with transforming DNA from $s t r-r$ strains of Moraxella nonliquefaciens repeatedly yielded a few str-r colonies, whereas corresponding controls were negative. For example, following treatment of $N$. catarrhalis strain $8313\left(8.9 \times 10^{5}\right.$ organisms $/ \mathrm{ml}$.) with DNA from $M$. nonliquefaciens 18522 str-r, fourteen colonies developed on a set of eight plates which had received a total inoculum of $2 \mathrm{ml}$. These colonies were picked, and were found to be similar to the parental strain in all characteristics examined except for resistance to dihydrostreptomycin. DNA preparations 2 and 3 (of Table 1) were extracted from two separate colony isolates. Similarly, in an experiment with a higher concentration $\left(1 \cdot 6 \times 10^{7}\right.$ organisms $/ \mathrm{ml}$.) of the same recipient strain, the deoxyribonucleaseinactivated control showed no colonies, whereas 94 colonies $/ \mathrm{ml}$. were obtained from a test with DNA from $M$. nonliquefaciens MHD 2/10 str-r. Some of these str-r colonies were examined as before, and cultures of one isolate were made for extraction of DNA prep. 5. 
Tests of Moraxella nonliquefaciens recipients against DNAs from str-r (mutant) strains of Neisseria catarrhalis yielded only a rare colony. From two of these str-r isolates DNA (preps. 6 and 12) was extracted. In addition, DNA preps. 7-11 were obtained from str-r strains of $\boldsymbol{M}$. nonliquefaciens which arose in tests with DNA preps. 1-4.

Two experimental approaches were used to investigate the origin of the dihydrostreptomycin-resistant colonies arising in these intergeneric tests. The first involved examining the transforming activities of the twelve DNA preparations obtained in preliminary tests. It was reasoned that a mixed genetic background should be revealed if the str- $r$ determinant had been introduced by transformation, since other studies have shown that the DNA transformants obtained in interspecific crosses may retain some genetic specificity characteristic of the donor species (Leidy, Hahn \& Alexander, 1956; Schaeffer, 1958; Marmur, Seaman \& Levine, 1963; Krauss \& MacLeod, 1963). If this were so in our system, DNA from a str-r strain derived by transformation in the cross Neisseria catarrhalis str-s cells $\times$ Moraxell anonliquefaciens str- $r$ DNA, should elicit transformation of $M$. nonliquefaciens from $s t r-s$ to $s t r-r$ at a higher frequency than that of DNA from spontaneous str-r mutants of $N$. catarrhalis. On the other hand, if the str-r clone of $N$. catarrhalis arose not by transformation but by mutation, its DNA should not elicit more transformants from a recipient population of $M$. nonliquefaciens than that of a proven str-r mutant of $N$. catarrhalis.

The results of tests with DNA preparations 1-5 and 7-12 (Table 1) are in agreement with the view that the str-r determinant of each was introduced by transformation. Thus, the transforming capacity of DNA prep. 5 for Moraxella nonliquefaciens MHD 2/10 was 480 times higher than that of a corresponding mutant strain (0.0146\% transformation compared with $0.00003 \%$ elicited by prep. 14); and decrease of activity for Neisseria catarrhalis 8313 was less than twofold. Similarly, DNA prep. 12, obtained from $M$. nonliquefaciens MHD 2/10 str-r, elicited transformation of $N$. catarrhalis 8313 at a frequency 333 times higher than that of prep. 16. In this case, unexpectedly, the DNA (prep. 12; also 10 and 11) transformed $M$. nonliquefaciens MHD 2/10 recipient organisms with an efficiency even higher than that of prep. 16. A possibly analogous case was recorded for Bacillus subtilis by Marmur, Seaman \& Levine (1963).

On the other hand, prep. 6 (as well as prep. 8, to be discussed later) exhibited low transforming activity for Neisseria catarrhalis, comparable to that of prep. 15 . In the absence of increased homology or other evidence of transformation, the mutational origin of the str- $r$ determinant of prep. 6 must be inferred.

The second approach to the problem of the origin of the str-r colonies involved a study of the response of Neisseria catarrhalis 8313 recipient organisms as related to time of exposure and concentration of DNA of Moraxella nonliquefaciens. A single reaction mixture (suspension +DNA prep., at $30^{\circ}$ ) was sampled repeatedly during a 30 min. period, beginning at $1 \mathrm{~min}$. Each sample was added directly to broth containing deoxyribonuclease, and a suitable volume of this dilution was promptly plated.

Genetic events were rapidly initiated by the DNA preparations from Moraxella nonliquefaciens (Fig. 1, curves 2, 3, 4). The time course of these reactions was similar to that of the standard transforming DNA of Neisseria catarrhalis 8313 str-r (curve 1). 


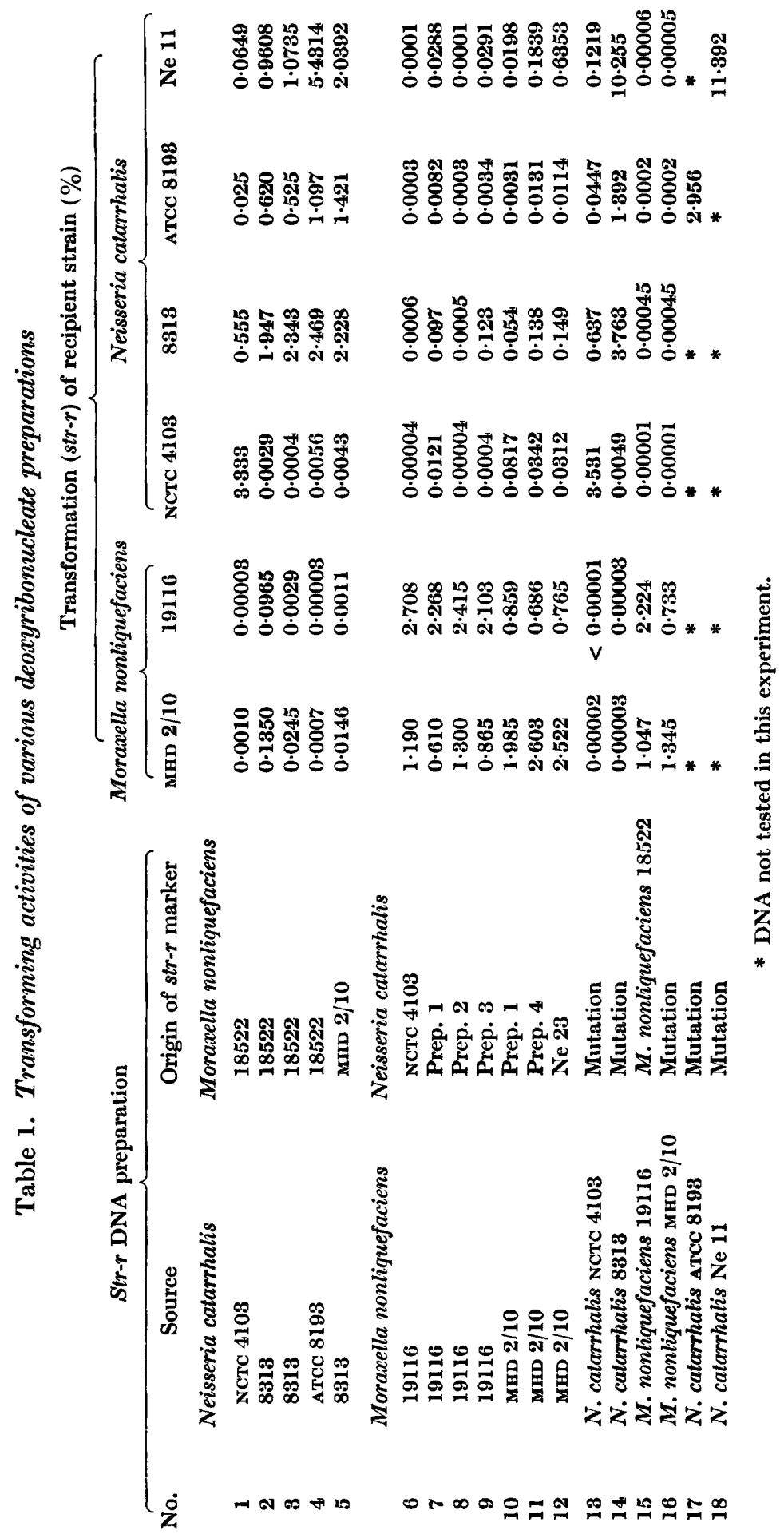


Moreover, it resembled transformation of other bacteria (e.g. Young \& Spizizen, 1961; Goodgal, 1961). Exposure of the organisms for a period of $5 \mathrm{~min}$. to autologous DNA (curve 1) and to $M$. nonliquefaciens str-r DNA (curve 4), each tested at a final concentration of $5 \mu \mathrm{g}$. $/ \mathrm{ml}$., was sufficient to initiate 32 and $30 \%$, respectively, of the total (30 min.) genetic events. Higher yields for $5 \mathrm{~min}$. samples $(65 \%$, curve 2; $43 \%$, curve 3) were obtained with the DNAs at $10 \mu \mathrm{g} . / \mathrm{ml}$. In contrast, the time required for doubling the total population under these conditions was about $85 \mathrm{~min}$. Mutant str-r clones were not found in the deoxyribonuclease-inactivated DNA controls that accompanied each of these experiments.

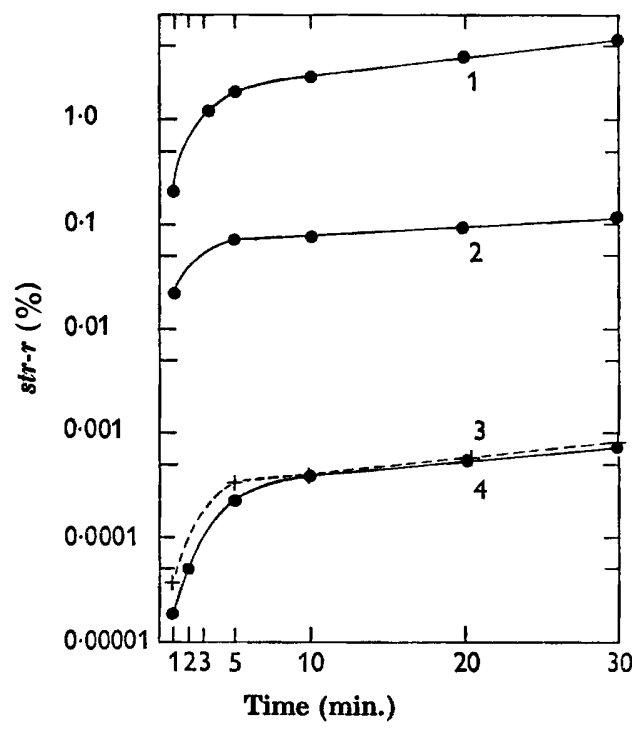

Fig. 1

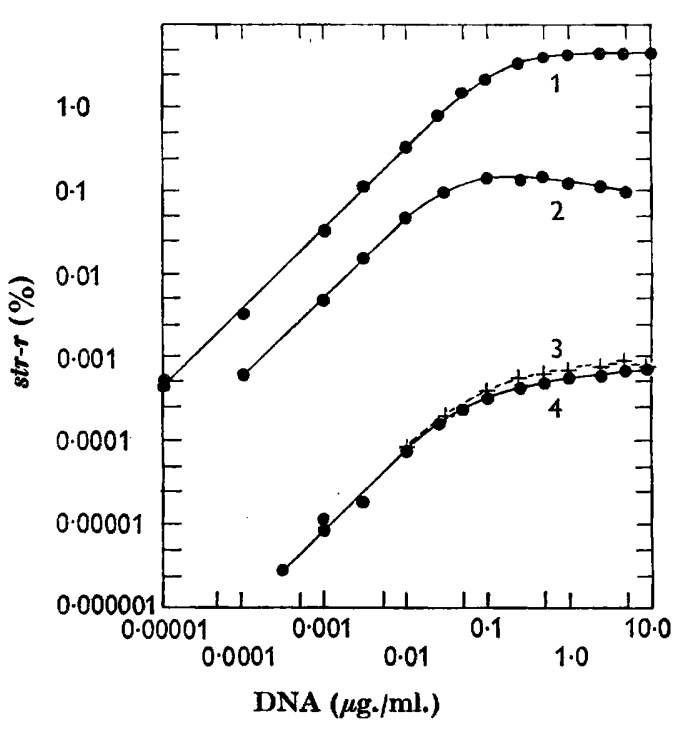

Fig. 2

Fig. 1. Effect of time of exposure to active DNA on the genetic response of Neisseria catarrhalis strain 8313. Curves correspond to 4 expts., each with a different DNA prep.: (1) N. catarrhalis 8318 str-r (prep. 14, Table 1), final concentration $5 \mu \mathrm{g} . / \mathrm{ml}$.; (2) Moraxella nonliquefaciens 19116 str-r (intergenus transformant, prep. 7 , Table 1 ), $10 \mu \mathrm{g} . / \mathrm{ml}$; (3) M. nonliquefaciens MHD 2/10 str-r (prep. 16, Table 1), $10 \mu \mathrm{g} . / \mathrm{ml}$; (4) M. nonliquefaciens 19116 str-r (prep. 15, Table 1), $5 \mu \mathrm{g}$./ml. Exposure to DNA was terminated at each time indicated by adding a sample of the reaction mixture to broth containing $5 \mu \mathrm{g}$. deoxyribonuclease $/ \mathrm{ml}$.

Fig. 2. Effect of DNA concentration on the genetic response of Neisseria catarrhalis strain 8313 . Time of exposure, $30 \mathrm{~min}$. at $30^{\circ}$; DNA preps., as given for Fig. 1 .

Tests were made of the effect of concentration of DNA on the genetic response of Neisseria catarrhalis. The results with strain 8313 recipient organisms are plotted in Fig. 2. The linear portion of each curve at concentrations below $0 \cdot 1 \mu \mathrm{g}$. DNA/ml., and the plateau at relatively high concentrations (curves $1,3,4$ ) are typical of the results obtained with other transformable bacteria (Hotchkiss, 1957; Young \& Spizizen, 1961; Goodgal, 1961). The downward inflexion of the plateau region of curve 2 (possibly resembling inhibition obtained with mixtures of DNA preparations by Hotchkiss, 1957, and by Schaeffer, 1958) is a repeatable finding, which is thus far unexplained. 


\section{DISCUSSION}

DNA preparations from streptomycin-resistant strains of Moraxella nonliquefaciens have genetic activity for streptomycin-susceptible recipient populations of Neisseria catarrhalis. Genetic transformation was established as the basis of this $s t r-s$ to $s t r-r$ change by the typical time-response and DNA concentration-response curves, and by the high reciprocal transforming activity of DNA preparations extracted from the intergeneric transformants. In addition, certain inferences can be made concerning the transfer of information between these organisms.

In order that comparisons of cellular response to various heterologous DNAs should be reliable, the tests with a given recipient strain were carried out simultaneously with samples of one cellular suspension and each of the DNA preparations (Table 1). The ratio, transformation by heterologous DNA $\times 1000 /$ transformation by autologous DNA, will be referred to as the str-r recognition index (RI). To facilitate comparison and discussion, these ratios are given in Table 2. Use of the term str-r RI, rather than a term such as intergeneric transformation ratio, in discussing these results is expedient at present in view of the possibility that $R I$ values involving genetic determinants of other characteristics may show little correlation.

Table 2. Str-r recognition indexes*

\begin{tabular}{|c|c|c|c|c|c|c|c|c|}
\hline \multirow[b]{3}{*}{ No. } & & & \multicolumn{6}{|c|}{ Recipient strain } \\
\hline & \multicolumn{2}{|c|}{ DNA preparationt } & \multicolumn{2}{|c|}{$\begin{array}{c}\text { Moraxella } \\
\text { nonliquefaciens }\end{array}$} & \multicolumn{4}{|c|}{ Neisseria catarrhalis } \\
\hline & Organism & $\begin{array}{l}\text { Transformed } \\
\text { by DNA of }\end{array}$ & MHD $2 / 10$ & 19116 & NCTC 4103 & 8313 & ATCc 8193 & $\mathrm{Ne} 11$ \\
\hline $\begin{array}{r}1 \\
7 \\
10\end{array}$ & $\begin{array}{l}N \text { vetc } 4103 \\
M 19116 \\
M \text { MHD } 2 / 10\end{array}$ & $\begin{array}{l}M 18522 \\
\text { Prep. } 1 \\
\text { Prep. } 1\end{array}$ & $\begin{array}{c}0 \cdot 8 \\
454 \\
1475\end{array}$ & $\begin{array}{l}0.01 \\
837 \\
317\end{array}$ & $\begin{array}{r}945 \\
3 \\
23\end{array}$ & $\begin{array}{r}147 \\
26 \\
14\end{array}$ & $\begin{array}{l}9 \\
3 \\
1\end{array}$ & $\begin{array}{l}6 \\
3 \\
2\end{array}$ \\
\hline $\begin{array}{r}11 \\
12 \\
4 \\
5\end{array}$ & $\begin{array}{l}M \text { MHD } 2 / 10 \\
M \text { MHD } 2 / 10 \\
N \text { ATCC } 8193 \\
N 8313\end{array}$ & $\begin{array}{l}\text { Prep. } 4 \\
N \text { Ne } 23 \\
M 18522 \\
M \text { MHD 2/10 }\end{array}$ & $\begin{array}{c}1935 \\
1875 \\
0 \cdot 5 \\
11\end{array}$ & $\begin{array}{l}253 \\
282 \\
0 \cdot 01 \\
0 \cdot 4\end{array}$ & $\begin{array}{c}10 \\
9 \\
1 \cdot 6 \\
1 \cdot 2\end{array}$ & $\begin{array}{r}37 \\
40 \\
656 \\
592\end{array}$ & $\begin{array}{r}4 \\
4 \\
371 \\
481\end{array}$ & $\begin{array}{r}16 \\
56 \\
477 \\
179\end{array}$ \\
\hline $\begin{array}{l}\mathbf{2} \\
3 \\
8 \\
9\end{array}$ & $\begin{array}{l}N 8313 \\
N 8313 \\
M 19116 \\
M 19116\end{array}$ & $\begin{array}{l}M 18522 \\
M 18522 \\
\text { Prep. } 2 \\
\text { Prep. } 3\end{array}$ & $\begin{array}{r}100 \\
18 \\
967 \\
643\end{array}$ & $\begin{array}{r}36 \\
1 \\
892 \\
777\end{array}$ & $\begin{array}{l}0.8 \\
0.1 \\
0.01 \\
0.1\end{array}$ & $\begin{array}{l}517 \\
623 \\
0 \cdot 14 \\
33\end{array}$ & $\begin{array}{l}210 \\
177 \\
0 \cdot 1 \\
1\end{array}$ & $\begin{array}{l}85 \\
94 \\
0 \cdot 01 \\
3\end{array}$ \\
\hline $\begin{array}{r}6 \\
15\end{array}$ & $\begin{array}{l}M 19116 \\
M \\
19116\end{array}$ & $\bar{M}_{18522}$ & $\begin{array}{l}883 \\
778\end{array}$ & $\begin{array}{r}1000 \\
822\end{array}$ & $\begin{array}{l}0.011 \\
0.004\end{array}$ & $\begin{array}{l}0 \cdot 16 \\
0 \cdot 12\end{array}$ & $\begin{array}{l}0.09 \\
0.05\end{array}$ & $\begin{array}{l}0.012 \\
0.005\end{array}$ \\
\hline
\end{tabular}

The str- $r$ RI indicates the comparative ability of a given recipient strain to recognize and integrate the $s t r-r$ determinant of a particular DNA preparation. Prediction of RI for any given DNA may be erroneous when it is based on general knowledge of the cellular morphology of the DNA donor and recipient strains or of their DNA base average compositions. Low RI values were characteristic of the interaction between Neisseria catarrhalis diplococci and DNA from the rod-shaped organism Moraxella nonliquefaciens (preps. 6, 15, 16). A minimum requirement for genetic transformation has been thought to be similarity of the guanine + cytosine $(G+C)$ contents of the DNAs of donor and recipient organisms (Marmur, Seaman \& Levine, 1963). If this view has predictive value, the highest $R I$ value should be found in tests involving $N$. catarrhalis NCTC 4103 and $M$. nonliquefaciens, as the $\mathrm{G}+\mathrm{C}$ contents of their DNAs are practically the same (about $44.4 \%$, Catlin \& Cunningham, 
$1964 a, b)$. Of the strains examined, however, $N$. catarrhalis $8313(42 \cdot 3 \% \mathbf{G}+\mathrm{C})$ was the most efficient in integrating the str-r marker of $M$. nonliquefaciens.

RI may be greatly affected by genetic manipulation of the DNA donor strain. Thus, an RI of 56 was found in a test of Neisseria catarrhalis Ne $11(41 \% \mathrm{G}+\mathrm{C})$ with a DNA preparation (12, Table 2) from Moraxella nonliquefaciens MHD 2/10 $(44.4 \% \mathrm{G}+\mathrm{C})$. The transformation event which introduced the str-r determinant of $N$. catarrhalis $\mathrm{Ne} 23(42 \cdot 2 \% \mathrm{G}+\mathrm{C})$ into $M$. nonliquefaciens, producing the 'interbreed' strain from which prep. 12 was obtained, at the same time increased the RI by 13,000 (56 compared with 0.004 , the RI for prep. 16).

Thus, recipient strains of both Moraxella nonliquefaciens and Neisseria catarrhalis recognized the str-r region of DNA from a first-step transformant, thereby revealing its mixed genetic background. DNAs from four strains which resulted from secondstep transformations (Table 2, preps. 7, 10, 11, and 9) were recognized also by recipients of both species. Furthermore, there was evidence of 'self recognition'. In tests of $N$. catarrhalis NCTC 4103 recipient cocci with DNA from $M$. nonliquefaciens transformants, the RI value was higher when the str-r determinant came from strain NCTC 4103 rather than from other $N$. catarrhalis strains (compare prep. 7 with 9 , and 10 with 11).

Although the homology established during the first transformation step tended to be retained by the second-step transformant DNAs (e.g. compare prep. 12 with 11), one instructive exception was found. DNA prep. 8 was obtained from a strain which arose as an isolated colony following treatment of Moraxella nonliquefaciens 19116 $s t r-s$ recipient organisms with DNA prep. 2 (Neisseria catarrhalis first-step str- $r$ transformant). RI values obtained in tests of prep. 8 against $N$. catarrhalis strains were not significantly higher than those of prep. 15 or 6. This finding, which differs markedly from results with the corresponding preps. 3 and 9, could be interpreted as indicating that the isolate was a spontaneous mutant. Arguing against this interpretation is the high transformation frequency $(0.1 \%)$ calculated for the test in which the isolate was derived; the colony selected was one among 10,000. The alternative and preferred explanation, that the isolate was a transformant, is discussed below.

Studies of transformation of species of the genera Haemophilus, Neisseria, Bacillus and Streptococcus have shown in general that frequencies of transformation are high between closely related strains and lower between members of different species. This tendency has been related to the degree of homology of the DNA molecules of donor and recipient strains (Marmur, Falkow \& Mandel, 1963). Attention has focused recently on molecular microhomologies, now that it is clear that genetic information carried by transforming DNA lies in the particular sequences in which the nucleotides (and their component bases) are associated. Complementary nucleotide sequences in DNAs from different though related micro-organisms have been detected by duplex strand formation by using physical methods (discussed by Marmur, Schildkraut \& Doty, 1961; Marmur, Falkow \& Mandel, 1963; McCarthy $\&$ Bolton, 1963). The recognition which is associated with genetic transformation likewise appears to involve interaction of corresponding nucleotide sequences of resident (recipient cell) and introduced (transforming) DNA molecules. The subsequent process of integration of the introduced genetic information remains problematic (Ravin, 1961). Nevertheless, information is accumulating on the 
subject of the length of a sequence that can be integrated during a transformation event. That the integrated sequence is only a small fraction of the total genome is indicated by the fact that many genetic determinants are introduced independently. However, recent studies have revealed a number of linked markers, i.e. genetic determinants that tend to be transferred together. In Neisseria catarrhalis, as in Haemophilus influenzae (van Sluis \& Stuy, 1962), the str-r determinant appears to be closely linked to that for kanamycin resistance (Catlin, 1963). In Bacillus subtilis thirteen different genetic loci are carried by a single transforming molecule (Nester, Schafer \& Lederberg, 1963). The results of various analyses suggest that the integrated sequences may be of varying length, and that small regions are introduced in transformations more frequently than larger ones (Hotchkiss \& Evans, 1958; Ephrussi-Taylor, 1960, 1961; Ravin, 1961).

The $s t r-r$ RI values of Table 2 provide a basis for three inferences concerning the nucleotide sequence integrated during a transformation event. It is assumed here that the str-r determinants of Neisseria catarrhalis and Moraxella nonliquefaciens are similar; otherwise, the information which is meaningful for organisms of one species should be nonsense for those of the other. However, if integration involved the $s t r-r$ determinant alone, DNA subsequently extracted from the transformant would not be expected to exhibit differences referable to the origin of the str-r determinant. The evidence of enhanced recognizability of DNAs from Neisseria-Moraxella str-r transformants thus suggests that integration involved sequences longer than the $s t r-r$ determinant itself. Such a theory, employed by Schaeffer (1958) to explain differences between frequencies of interspecific and intraspecific transformation of Haemophilus, is supported by evidence obtained in studies of interspecific transformation of Bacillus (Marmur, Seaman \& Levine, 1963). Secondly, the evidence relating to DNA preps. 2 and 3 , which were from str- $r$ transformants derived in the same test, suggests that they differ in respect to the length of the $M$. nonliquefaciensspecific portion which was integrated. The particular sequence of prep. 2 which bears the $s t r-r$ determinant includes a longer stretch characteristic of $\boldsymbol{M}$. nonliquefaciens than is present in prep. 3, thus accounting for the higher RI values obtained in second-step transformation tests with $M$. nonliquefaciens strains MHD 2/10 and 19116 (Table 2). Thirdly, it is inferred that DNA prep. 8 contains the $s t r-r$ determinant of prep. 2 associated with a region which is not significantly longer than that originally taken from $M$. nonliquefaciens 18522 . Thus, during the transformation event a tendency to integrate short sequences resulted in elimination of the peripheral $N$. catarrhalis-specific nucleotides required for recognition by $N$. catarrhalis. On the other hand, prep. 9 contains the shorter $M$. nonliquefaciens-specific sequence of prep. 3, together with some adjacent nucleotides which bear the specificity of N. catarrhalis.

Thus, unknown factors appear to affect the length of the nucleotide sequences which are integrated by different organisms of the same treated suspension. If relationships between bacteria are to be estimated on the basis of transformation frequencies, it is evident that a number of transformants should be analysed, as has been done here. Reciprocal tests clearly are useful. In addition, however, more than a single genetic determinant should be investigated. Although genetic homology involving the str-r determinants has been demonstrated between strains of Moraxella nonliquefaciens and Neisseria catarrhalis, the significance of this 
finding remains debatable. It is hoped that further genetic studies of these species may provide a sounder basis for judgement concerning the degree of relationship between the two species.

This investigation was supported by research grant AI 02353-06 from the National Institutes of Health, U.S. Public Health Service.

\section{REFERENCES}

Bracco, R. M., Krauss, M. R., Roe, A. S. \& MacLeod, C. M. (1957). Transformation reactions between pneumococcus and three strains of streptococci. J. exp. Med. 106, 247.

Caturn, B. W. (1963). Transformation by deoxyribonucleate preparations of different average base composition. Microbial Genet. Bull. 19, 5.

Catuin, B. W. \& Cunningham, L. S. (1961). Transforming activities and base contents of deoxyribonucleate preparations from various neisseriae. J. gen. Microbiol. 26, 303.

Catirn, B. W. \& CunninghaM, L.S. $(1964 a)$. Genetic transformation of Neisseria catarrhalis by deoxyribonucleate preparations having different average base compositions. J. gen. Microbiol. 37, 341.

Catlin, B. W. \& Cunningham, L. S. (1964b). Transforming activities and base composition of deoxyribonucleates from strains of Moraxella and Mima. J. gen. Microbiol. 37, 353.

Ephrussi-TayLor, H. (1960). On the biological functions of deoxyribonucleic acid. Symp. Soc. gen. Microbiol. 10, 132.

EPHRUSSi-Taylor, H. (1961). Recombination analysis in microbial systems. In Grozth in Living Systems. Ed. by M. X. Zarrow, p. 39. New York: Basic Books.

Goodgal, S. H. (1961). Studies on transformations of Hemophilus influenzae. IV. Linked and unlinked transformations. J. gen. Physiol. 45, 205.

Henriksen, S. D. (1952). Moraxella: classification and taxonomy. J. gen. Microbiol. 6, 318.

Hoтchкiss, R. D. (1957). Criteria for quantitative genetic transformation of bacteria. In The Chemical Basis of Heredity. Ed. by W. D. McElroy \& B. Glass. Baltimore: The Johns Hopkins Press.

Hotchisss, R. D. \& Evans, A. H. (1958). Analysis of the complex sulfonamide resistance locus of pneumococcus. Cold Spr. Harb. Symp. quant. Biol. 23, 85.

KraUSS, M. R. \& MACLEOD, C. M. (1963). Intraspecies and interspecies transformation reactions in pneumococcus and streptococcus. J. gen. Physiol. 46, 1141.

Leidy, G., Hahn, E. \& Alexander, H. E. (1956). On the specificity of the desoxyribonucleic acid which induces streptomycin resistance in Hemophilus. J. exp. Med. 104, 305.

Marmur, J., Falkow, S. \& Mandel, M. (1963). New approaches to bacterial taxonomy. Annu. Rev. Microbiol. 17, 329.

Marmur, J., Schildkraut, C. L. \& Doty, P. (1961). The reversible denaturation of DNA and its use in studies of nucleic acid homologies and the biological relatedness of microorganisms. J. Chim. phys. p. 945.

Marmur, J., Seaman, E. \& Levine, J. (1963). Interspecific transformation in Bacillus. J. Bact. 85, 461.

McCarthy, B. J. \& Bolton, E. T. (1963). An approach to the measurement of genetic relatedness among organisms. Proc. nat. Acad. Sci., Wash. 50, 156.

Murray, R. G. E. \& Truant, J. P. (1954). The morphology, cell structure, and taxonomic affinities of the Moraxella. J. Bact. 67, 13.

Nester, E. W., Schafer, M. \& Lederberg, J. (1963). Gene linkage in DNA transfer: a cluster of genes concerned with aromatic biosynthesis in Bacillus subtilis. Genetics, 48 , 529.

Ravin, A. W. (1961). The genetics of transformation. Advanc. Genet. 10, 61. 
RAvin, A. W. \& DE SA, J. D. H. (1964). Genetic linkage of mutational sites affecting similar characters in pneumococcus and streptococcus. J. Bact. 87, 86.

SchaEfFER, P. (1958). Interspecific reactions in bacterial transformation. Symp. Soc. exp. Biol. 12, 60.

van Suuis, C. A. \& Stuy, J. H. (1962). On the inactivation of transforming deoxyribonucleic acid by heat. Biochem. biophys. Res. Comm. 7, 213.

Young, F. E. \& SpIzizen, J. (1961). Physiological and genetic factors affecting transformation of Bacillus subtilis. J. Bact. 81, 823. 